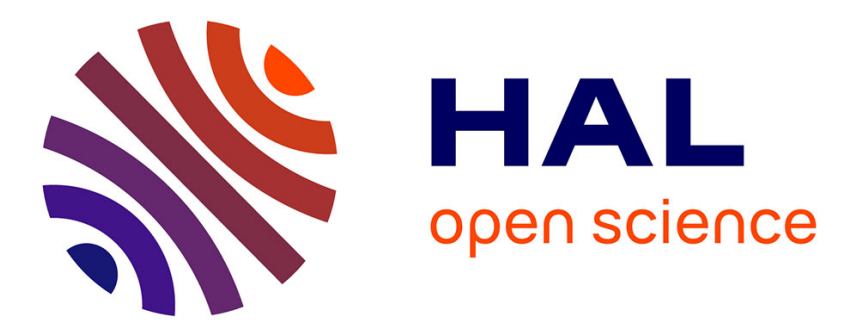

\title{
Modelling of a hydrogen permeation process from gas phase towards liquid sodium and experimental set-up for prototype testing
}

Pietro Brazzale, Aurélien Chassery, Thierry Gilardi, Christian Latgé, Xuan Mi Meyer, Xavier Joulia

\section{To cite this version:}

Pietro Brazzale, Aurélien Chassery, Thierry Gilardi, Christian Latgé, Xuan Mi Meyer, et al.. Modelling of a hydrogen permeation process from gas phase towards liquid sodium and experimental set-up for prototype testing. Chemical Engineering Research and Design, 2020, 159, pp.555-564. 10.1016/j.cherd.2020.05.012 . hal-03031866

\section{HAL Id: hal-03031866 https://hal.science/hal-03031866}

Submitted on 30 Nov 2020

HAL is a multi-disciplinary open access archive for the deposit and dissemination of scientific research documents, whether they are published or not. The documents may come from teaching and research institutions in France or abroad, or from public or private research centers.
L'archive ouverte pluridisciplinaire HAL, est destinée au dépôt et à la diffusion de documents scientifiques de niveau recherche, publiés ou non, émanant des établissements d'enseignement et de recherche français ou étrangers, des laboratoires publics ou privés. 


\section{OATAO \\ Open Archive Toulouse Archive Ouverte}

\section{Open Archive Toulouse Archive Ouverte}

OATAO is an open access repository that collects the work of Toulouse researchers and makes it freely available over the web where possible

This is an author's version published in: http://oatao.univ-toulouse.fr/26138

\section{Official URL:}

https://doi.org/10.1016/j.cherd.2020.05.012

\section{To cite this version:}

Brazzale, Pietro and Chassery, Aurélien and Gilardi, Thierry and Latgé, Christian and Meyer, Xuân-Mi and Joulia, Xavier Modelling of a hydrogen permeation process from gas phase towards liquid sodium and experimental set-up for prototype testing. (2020) Chemical Engineering Research and Design, 159. 555-564. ISSN 0263-8762

Any correspondence concerning this service should be sent to the repository administrator: tech-oatao@listes-diff.inp-toulouse.fr 


\title{
Modelling of a hydrogen permeation process from gas phase towards liquid sodium and experimental set-up for prototype testing
}

\author{
Pietro Brazzale ${ }^{a, *}$, Aurélien Chassery ${ }^{a}$, Thierry Gilardi $^{a}$, Christian Latgé $^{a}$, \\ Xuân-Mi Meyer ${ }^{b}$, Xavier Joulia ${ }^{b}$ \\ ${ }^{a}$ CEA, DEN, Cadarache, DTN, F-13108 Saint-Paul-lez-Durance, France \\ ${ }^{\mathrm{b}}$ Laboratoire de Génie Chimique, Université de Toulouse, CNRS, INP, UPS, Toulouse, France
}

\begin{abstract}
A B S T R A C T
Hydrogen permeation through nickel dense membrane applied to Sodium cooled Fast Reac-

tors has been studied theoretically and experimentally. In order to investigate the coupling of nickel membrane with external gas and sodium flows, an analytical model based on mass transfer resistances is developed. A sensitivity analysis showed that, for enough thick membranes and high sodium velocities, the nickel resistance has the most important effect. A permeator prototype constituted of four Ni201 tubular membranes, has been designed: experimental tests at pilot-scale are carried out at different temperatures, gas pressures and flowrates, both in gas-vacuum and gas-sodium configuration. Results for permeation against vacuum demonstrate that hydrogen diffusion within the membrane is the limiting step, in accordance with previous literature results obtained for pure nickel permeation experiments.
\end{abstract}

Keywords:

Hydrogen

Permeation

Sodium

Nickel

Tritium

Sodium Fast Reactor

\section{Introduction}

In the framework of SFRs (Sodium Fast Reactors), the management of tritium contamination in coolant circuits (especially liquid sodium circuits), and the control of tritium release in atmosphere is one main safety issue. In order to capture and recuperate this tritium, a sufficient hydrogen concentration in liquid sodium is necessary, to reach the saturation value, allowing hydrogen and tritium co-crystallization in cold traps (Latge, 2009). During operation of classical SFR's concept equipped with an Energy Conversion System based on Rankine cycle (water and steam in Steam-Generator Units), a hydrogen supply is naturally provided from aqueous corrosion and hydrazine decomposition inside the steam generator tubes. Hydrazine is used to decrease $O$ dissolved content in water, and consequently aqueous corrosion of structural

\footnotetext{
* Corresponding author.

E-mail address: pietro.brazzale@cea.fr (P. Brazzale).
}

material (Latge, 2009). If this contribution is not sufficient, or in the case of innovative reactors based on Brayton cycle Energy Conversion System (Cachon et al., 2012), an external and independent process is necessary to control the introduction of a required hydrogen flux into liquid sodium. The permeation through nickel dense membranes has been identified as the most suitable technical solution: it is supposed to bring some advantages in terms of security and process control, based on previous experimental feedback, from relevant research activities.

Several studies consider hydrogen permeation, involving a gas phase on both membrane's sides (gas-gas configuration) (Webb, 1964; Robertson, 1973); in this case, the Richardson's law (Richardson et al., 1904) is commonly accepted to describe the hydrogen permeation flowrate in steady state conditions, if temperature and membrane thickness are high enough $\left(\delta>100 \mu \mathrm{m}\right.$ and $\left.\mathrm{T}>300^{\circ} \mathrm{C}\right)$. This law results from the combination of the 1st Fick's diffusion law and the Sieverts law, which describes the hydrogen equilibrium between gas and liquid metal phase: several authors found experimental evidences 


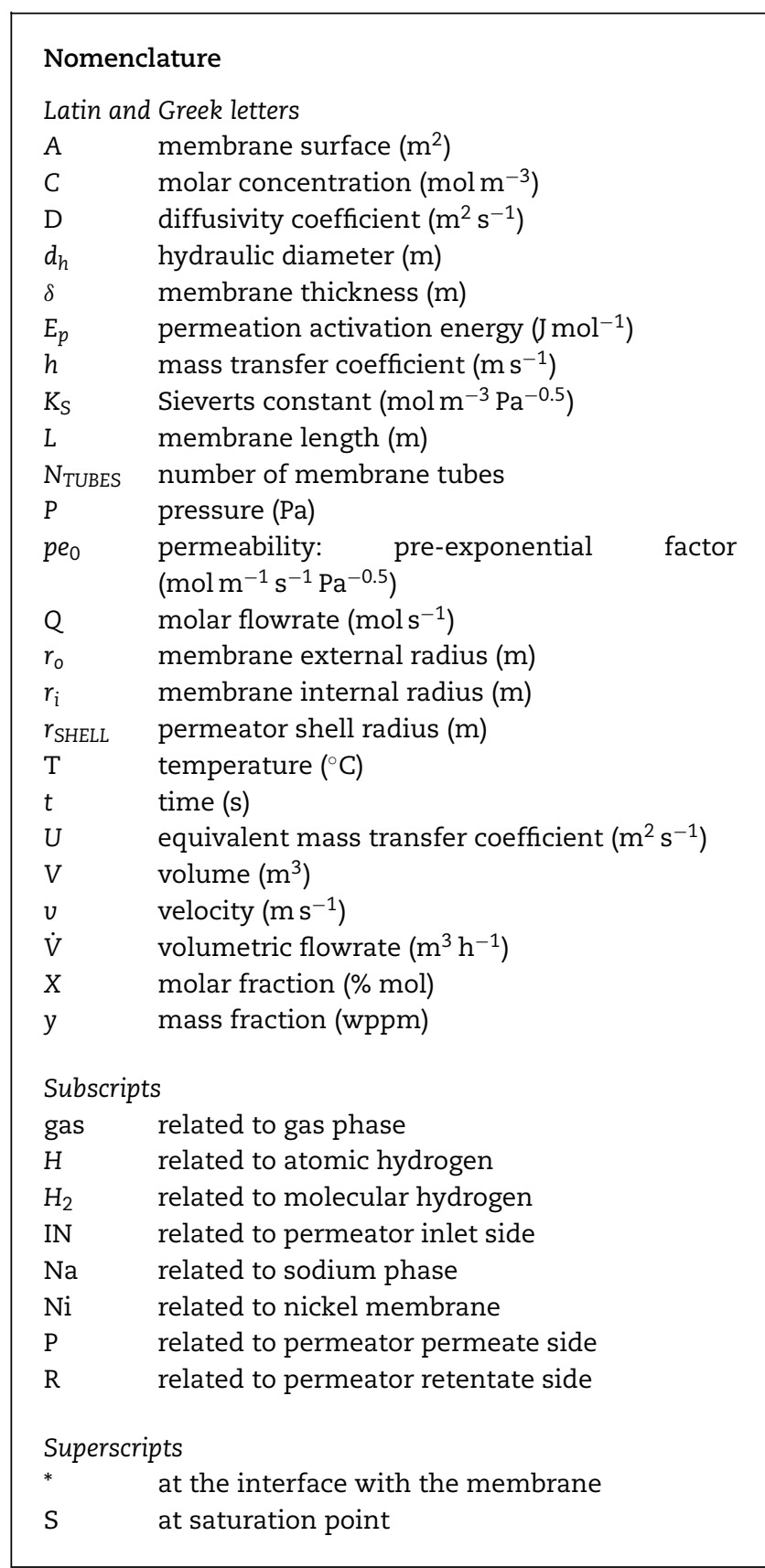

of its validity for nickel membranes in these parameters' range (Robertson, 1973; Sakamoto, 2000). In this case, the ratelimiting step of permeation process is the hydrogen atomic diffusion through the membrane metallic bulk; any other phenomenon like surface or trapping effect, i.e. adsorption, is neglected, since they are faster than diffusion. When a gas mixture is used as feed gas instead of pure hydrogen, an additional mass transfer resistance in the gas phase could have an influence on hydrogen permeation; it is given from an accumulation of the less permeable species and a depletion of the more permeable ones in the boundary layer, at the membrane interface, thus resulting in a concentration gradient building up in the boundary layer. This effect, called "concentration polarization" (He et al., 1999), have found experimental evidences (Catalano et al., 2009; Faizal et al., 2015) for very thin membranes $(2.5-25 \mu \mathrm{m})$, when the metal resistance to diffusion is limited and the hydrogen permeation flowrate is comparable to the hydrogen feed flowrate.
Concerning the hydrogen dissolution in sodium, below the saturation concentration at a given temperature $\mathrm{T}$, it is dissolved in liquid sodium in the ionic form $\mathrm{H}^{-}$(Gnanasekaran, 1999; Maupre, 1978). Previous studies in nuclear research have given measurements of the Sievert equilibrium constant $\mathrm{K}_{\mathrm{S}, \mathrm{Na}}(\mathrm{T})$ (Whittingham, 1976), which links hydrogen concentration to its equilibrium partial pressure, as follows:

$\mathrm{K}_{\mathrm{S}, \mathrm{Na}}(\mathrm{T})=\frac{\mathrm{C}_{\mathrm{H}, \mathrm{Na}}}{\sqrt{\mathrm{P}_{\mathrm{H}_{2}}}} \quad\left[\right.$ wppm Torr $\left.^{-0.5}\right]$

Moreover, hydrogen permeation through nickel membranes is exploited in SFRs in order to obtain measurements of hydrogen concentrations in sodium, in the so called 'hydrogen-meters' (Vissers et al., 1974). In this case, hydrogen dissolved in sodium with a concentration permeates through nickel tubes to a vacuum side, according to the Richardson's law arranged in the following form:

$\mathrm{Q}=\frac{\mathrm{A}}{\delta} p e_{0} \exp ^{-E_{p} / \mathrm{RT}}\left(\frac{\mathrm{C}_{\mathrm{H}, \mathrm{Na}}}{\mathrm{K}_{\mathrm{S}, \mathrm{Na}}}-\sqrt{\mathrm{P}_{\mathrm{H}_{2}}, \text { vacuum }}\right) \quad\left[\mathrm{mol} \mathrm{s}^{-1}\right]$

where the square root of a fictive hydrogen partial pressure in sodium is implicitly considered according to Sieverts equilibrium expressed in Eq. (1.1). In particular, the membrane thickness of this application is much smaller than the membrane diameter, that the tubular geometry can be described by the ratio $(\mathrm{A} / \delta)$, without using the cylindrical coordinates. More recently, studies conducted at CEA (Paumel, 2012) compared the hydrogen detection by a system of four nickel tubes (SPHYNX) and an electrochemical detector developed by IGCAR (Gnanasekaran et al., 1990). The good agreement between the two methods suggests that the permeation Eq. (1.2) is valid, thus confirming the validity of Fick's diffusion law and Sieverts equilibrium hypothesis. On the other hand, very few studies were carried out when permeation takes place in the opposite sense, from a gas phase to liquid sodium: an application was studied by McKee (1977) to calibrate hydrogen metres but a poorly detailed study is available, while more recently Garcinuño et al. (2018) developed the same concept for Lead-Lithium in fusion applications.

Definitely, hydrogen permeation in gas-Na configuration provides some elements which are still unknown in literature. Firstly, when atomic hydrogen egress the membrane permeate side in contact with sodium, it is supposed to be reduced to $\mathrm{H}^{-}$ ion, instead of recombining to $\mathrm{H}_{2}$ molecules, like for gas-gas configuration. Then, the liquid sodium phase could provide an additional resistance to the global hydrogen mass transfer, which needs to be investigated depending on the physical parameters of the system. Finally, a good knowledge of the phenomena involved at interface in sodium media is needed, in order to correctly describe the overall mass transfer and to provide a validated process which, acting on the different physical parameters, is able to introduce a controlled hydrogen flowrate in sodium.

An analytical model, aiming to compare the different contributions to hydrogen mass transfer depending on the geometrical and physical parameters of the system, is presented in Section 2. The design of a permeator prototype and the concept of an experimental set-up is proposed in Section 3. Results of the prototype tests in a gas-against vacuum configuration are reported in Section 4. 


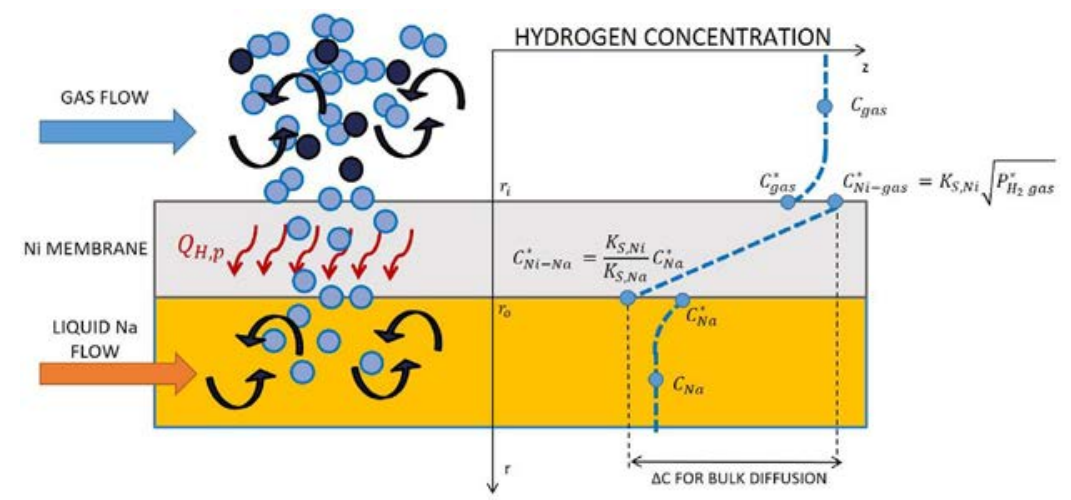

Fig. 1 - Hydrogen permeation physics in a shell and tube gas-Na configuration membrane.

\section{Hydrogen mass transfer resistances model}

The geometry considered to represent the permeator prototype is a tubular configuration, represented by a 2D axial symmetrical domain with the radial $(r)$ and axial $(z)$ coordinates (cf. Fig. 1), constituted by the following components:

- $r<r_{i}$ : a gas mixture containing molecular hydrogen $\left(\mathrm{H}_{2}\right)$ as diluted species, flowing inside the tubular nickel membrane, with a given mass flowrate along the axial direction $(z)$ at a given pressure;

- $r_{i}<r<r_{0}$ : a nickel tubular membrane, of a known thickness, separating the gas phase from the sodium phase. Atomic hydrogen $(\mathrm{H})$ permeates through the membrane from the most to the less concentrated side;

- $r>r_{0}$ : a liquid sodium phase, flowing with a given mass flowrate along the axial direction on the external side of the Ni membrane. Atomic hydrogen $(\mathrm{H})$ is dissolved in Na phase in the ionic form $\mathrm{H}^{-}$.

The following hypotheses are considered:

- the whole system is isotherm and adiabatic;

- steady state conditions;

- the membrane length is much greater than its thickness, thus the hydrogen mass transfer is only in the radial direction $r$;

- gas mixture and liquid sodium density are constant over the domain;

- ideal gas law validity;

- membrane bulk diffusion is the rate-limiting step of permeation process and no trapping or surface effect are considered, i.e. the permeation is described by the Richardson's law;

- chemical-physical equilibrium at interfaces follows the Sieverts law;

- pressure drop on gas phase is neglected.

When steady state condition is established, for each domain, on an infinitesimal portion of tube length $d z$, a hydrogen mass transfer rate in the radial direction can be defined as follows:

Gas phase: diffusive/convective transport of diatomic hydrogen molecules $\left(\mathrm{H}_{2}\right)$ from the gas phase bulk to the gas-membrane interface. The transfer flowrate is expressed in terms of hydrogen moles $(\mathrm{H})$ in order to be compared with the others; this is why a factor 2 appears in the equation.

$d Q_{\mathrm{H}, \text { gas }}=2 h_{\text {gas }}\left(C_{\mathrm{H}_{2} \text { gas }}-C_{\mathrm{H}_{2} \text { gas }}^{*}\right) * 2 \pi r_{i} d z \quad\left[\mathrm{~mol} \mathrm{~s}^{-1}\right]$

where $h_{\text {gas }}\left[\mathrm{m} \mathrm{s}^{-1}\right]$ is the hydrogen mass transfer coefficient of the gas mixture, obtained from a recommended mass transfer correlation for laminar flow through cylindrical pipes (Cussler, 2009). It depends from the gas velocity, the hydrogen diffusivity in the gas mixture and the membrane diameter and length.

$\frac{h_{\text {gas }}\left(2 r_{i}\right)}{D_{\mathrm{H}_{2}, \text { gas }}}=1.62\left(\frac{\left(2 r_{\mathrm{i}}\right)^{2} v}{L D_{\mathrm{H}_{2}, \text { gas }}}\right)^{1 / 3}$

Ni membrane: atomic hydrogen $(\mathrm{H})$ bulk diffusion through the nickel membrane is defined by the following infinitesimal correlation for cylindrical geometry

$d Q_{\mathrm{H}, \mathrm{Ni}}=D_{\mathrm{H}, \mathrm{Ni}}(\mathrm{T})\left(C_{\mathrm{H}, \mathrm{Ni}-\mathrm{gas}}^{*}-\mathrm{C}_{\mathrm{H}, \mathrm{Ni}-\mathrm{Na}}^{*}\right) * \frac{2 \pi}{\ln \left(r_{\mathrm{o}} / r_{\mathrm{i}}\right)} d z \quad\left[\mathrm{~mol} \mathrm{~s}^{-1}\right]$

where $D_{\mathrm{H}, \mathrm{Ni}}$ is the hydrogen diffusivity in nickel, estimated with the Robertson 'best fit' relationship (Robertson, 1973).

$D_{\mathrm{H}, \mathrm{Ni}}(\mathrm{T})=6.44 \times 10^{-7} e^{-40,237 / \mathrm{RT}} \quad\left[\mathrm{m}^{2} \mathrm{~s}^{-1}\right]$

Na phase: diffusive/convective transport of atomic hydrogen $(\mathrm{H})$ from the Na-membrane interface to the $\mathrm{Na}$ bulk. It depends from the Na physical parameters (density, viscosity, velocity), the hydrogen diffusivity in $\mathrm{Na}$ and the hydraulic diameter.

$d Q_{\mathrm{H}, \mathrm{Na}}=h_{\mathrm{Na}}\left(C_{\mathrm{H}, \mathrm{Na}}^{*}-C_{\mathrm{H}, \mathrm{Na}}\right) * 2 \pi r_{\mathrm{o}} d z \quad\left[\mathrm{~mol} \mathrm{~s}^{-1}\right]$

where $h_{\mathrm{Na}}\left[\mathrm{ms}^{-1}\right]$ is the hydrogen mass transfer coefficient in liquid sodium, obtained from mass transfer correlation for turbulent flow in pipes (Cussler, 2009).

$\frac{h_{\mathrm{Na}} d_{h}}{D_{\mathrm{H}, \mathrm{Na}}}=0.026 \mathrm{Re}^{0.8} \mathrm{Sc}^{1 / 3}$

In order to standardize the three above equations, an equivalent mass transfer coefficient $U\left[\mathrm{~m}^{2} \mathrm{~s}^{-1}\right]$ is defined for the three domains as follows:

$U_{\text {gas }}=h_{\text {gas }} * 2 \pi r_{i} \quad\left[\mathrm{~m}^{2} \mathrm{~s}^{-1}\right]$ 
$U_{\mathrm{Ni}}=D_{\mathrm{H}, \mathrm{Ni}}(\mathrm{T}) * \frac{2 \pi}{\ln \left(r_{\mathrm{o}} / r_{\mathrm{i}}\right)} \quad\left[\mathrm{m}^{2} \mathrm{~s}^{-1}\right]$

$\mathrm{U}_{\mathrm{Na}}=h_{\mathrm{Na}} * 2 \pi r_{0} \quad\left[\mathrm{~m}^{2} \mathrm{~s}^{-1}\right]$

Additionally, the following correlations for phase equilibrium defining hydrogen concentrations at the two membrane interfaces are considered:

$\mathrm{Ni}$-gas interface: Sieverts law equilibrium between molecular $\mathrm{H}_{2}$ in gas phase and atomic $\mathrm{H}$ adsorbed in the membrane substrate:

$$
\begin{aligned}
& C_{\mathrm{H}, \mathrm{Ni}-\mathrm{gas}}^{*}=\mathrm{K}_{\mathrm{S}, \mathrm{Ni}}(\mathrm{T}) \sqrt{p_{\mathrm{H}_{2}, \text { gas }}^{*}}=\mathrm{K}_{\mathrm{S}, \mathrm{Ni}}(\mathrm{T}) \sqrt{\mathrm{RT} \mathrm{C}_{\mathrm{H}_{2}, \text { gas }}^{*}} \\
& \quad\left[\mathrm{~mol} \mathrm{\textrm {m } ^ { - 3 } ]}\right.
\end{aligned}
$$

where $\mathrm{K}_{\mathrm{S}, \mathrm{Ni}}(\mathrm{T})\left[\mathrm{mol} \mathrm{m}^{-3} \mathrm{~Pa}^{-0.5}\right]$ is the Sieverts constant (or solubility) of atomic hydrogen in nickel, obtained by the Robertson 'best fit' relationship:

$\mathrm{K}_{\mathrm{S}, \mathrm{Ni}}(\mathrm{T})=0.832 e^{-12,477 / \mathrm{RT}} \quad\left[\mathrm{mol}_{\mathrm{H}} \mathrm{m}^{-3} \mathrm{~Pa}^{-0,5}\right]$

$\mathrm{Ni}-\mathrm{Na}$ interface: atomic hydrogen dissolved in nickel $\left(C_{\mathrm{H}, \mathrm{Ni}-\mathrm{Na}}^{*}\right)$ and in sodium $\left(\mathrm{C}_{\mathrm{H}, \mathrm{Na}}^{*}\right)$ both follow the Sieverts law, so that their concentrations can be expressed as function of an "equivalent" partial pressure, which corresponds to the equilibrium pressure that gaseous hydrogen molecules $\mathrm{H}_{2}$ would have if put in a gas phase in contact with them. Thus, if an equilibrium between $\mathrm{Ni}$ and $\mathrm{Na}$ hydrogen molecules exist, they should have the same equivalent partial pressure, corresponding to the following relationship:

$\frac{\mathrm{C}_{\mathrm{H}, \mathrm{Ni}-\mathrm{Na}}^{*}}{\mathrm{~K}_{\mathrm{S}, \mathrm{Ni}}(\mathrm{T})}=\frac{\mathrm{C}_{\mathrm{H}, \mathrm{Na}}^{*}}{\mathrm{~K}_{\mathrm{S}, \mathrm{Na}}(\mathrm{T})}$

where $\mathrm{K}_{\mathrm{S}, \mathrm{Na}}(\mathrm{T})\left[\mathrm{mol} \mathrm{m} \mathrm{m}^{-3} \mathrm{~Pa}^{-0.5}\right]$ is the Sieverts constant (or solubility) of atomic hydrogen in sodium, depending on temperature.

If one eliminates in Eq. (2.3) the terms $C_{\mathrm{H}, \mathrm{Ni}-\mathrm{gas}}^{*}$ and $\mathrm{C}_{\mathrm{H}, \mathrm{Ni}-\mathrm{Na}}^{*}$ by introducing the relationships (2.10) and (2.12), and by considering the coefficients defined by (2.7)-(2.9), the three hydrogen flowrates become:

$d \mathrm{Q}_{\mathrm{H}, \mathrm{gas}}=2 \mathrm{U}_{\text {gas }}\left(\mathrm{C}_{\mathrm{H}_{2} \text { gas }}-\mathrm{C}_{\mathrm{H}_{2} \text { gas }}^{*}\right) d z \quad\left[\mathrm{~mol} \mathrm{~s}^{-1}\right]$

$d Q_{H, N i}=U_{N i}(T)\left(K_{S, N i}(T) \sqrt{R T C_{H_{2}, \text { gas }}^{*}}-\frac{K_{S, N i}(T)}{K_{S, N a}(T)} C_{\mathrm{H}, \mathrm{Na}}^{*}\right) d z$

$\left[\mathrm{mol} \mathrm{s}^{-1}\right]$

$d Q_{\mathrm{H}, \mathrm{Na}}=U_{\mathrm{Na}}\left(\mathrm{C}_{\mathrm{H}, \mathrm{Na}}^{*}-\mathrm{C}_{\mathrm{H}, \mathrm{Na}}\right) d z \quad\left[\mathrm{~mol} \mathrm{~s}^{-1}\right]$

In order to respect the global hydrogen mass balance at steady state, the three hydrogen flowrates should be equal:

$\mathrm{dQ}_{\mathrm{H}, \mathrm{gas}}=d \mathrm{Q}_{\mathrm{H}, \mathrm{Ni}}=d \mathrm{Q}_{\mathrm{H}, \mathrm{Na}}=d \mathrm{Q}_{\mathrm{H}} \quad\left[\mathrm{mol} \mathrm{s}^{-1}\right]$

Therefore, by comparing the values of the three mass transfer coefficients, the impact of each physics on the global hydrogen transfer rate can be assessed and compared. Moreover, it can be noticed that $U_{\mathrm{Ni}}$ depends only on temperature

\begin{tabular}{|c|c|c|}
\hline \multicolumn{3}{|c|}{ Geometrical parameters input } \\
\hline$r_{i}$ & $\mathrm{~mm}$ & 3.3 \\
\hline$r_{0}$ & $\mathrm{~mm}$ & 3.6 \\
\hline$r_{\text {SHELL }}$ & $\mathrm{mm}$ & 21.2 \\
\hline$N_{\text {TUBES }}$ & - & 4 \\
\hline \multicolumn{3}{|c|}{ Physical parameters input } \\
\hline $\mathrm{T}$ & ${ }^{\circ} \mathrm{C}$ & 450 \\
\hline Qgas & $\mathrm{Nml} \mathrm{min}^{-1}$ & 200 \\
\hline$P_{\text {gas }}$ & bar (abs.) & 5 \\
\hline $\mathrm{X}_{\mathrm{H}_{2} \text { gas }}$ & $\% \mathrm{~mol}$ & 3 \\
\hline$\dot{\mathrm{V}}_{\mathrm{Na}}$ & $\mathrm{m}^{3} \mathrm{~h}^{-1}$ & 1 \\
\hline$y_{\mathrm{H}, \mathrm{Na}}$ & ppm & 0.05 \\
\hline \multicolumn{3}{|c|}{ Equations parameters } \\
\hline & $\mathrm{mol} \mathrm{m}^{-3} \mathrm{~Pa}^{-0.5}$ & 0.094 \\
\hline U & $\mathrm{mol} \mathrm{m}^{-3} \mathrm{~Pa}^{-0.5}$ & 0.357 \\
\hline$U_{\text {gas }}$ & $\mathrm{m}^{2} \mathrm{~s}^{-1}$ & $9.01 \times 10^{-5}$ \\
\hline$U_{\mathrm{Ni}}$ & $\mathrm{m}^{2} \mathrm{~s}^{-1}$ & $5.77 \times 10^{-8}$ \\
\hline$U_{\mathrm{Na}}$ & $\mathrm{m}^{2} \mathrm{~s}^{-1}$ & $2.23 \times 10^{-6}$ \\
\hline \multicolumn{3}{|l|}{ Outputs } \\
\hline $\mathrm{C}_{\mathrm{H}_{2} \text { gas }}$ & $\mathrm{mol}_{\mathrm{H}_{2}} \mathrm{~m}^{-3}$ & 2.495 \\
\hline $\mathrm{C}_{\mathrm{H}_{2} \text { gas }}^{*}$ & $\mathrm{~mol}_{\mathrm{H}_{2}} \mathrm{~m}^{-3}$ & 2.491 \\
\hline $\mathrm{C}_{\mathrm{H}, \mathrm{Ni}-\text { gas }}^{*}$ & $\mathrm{~mol}_{\mathrm{H}} \mathrm{m}^{-3}$ & 11.626 \\
\hline $\mathrm{C}_{\mathrm{H} \cdot \mathrm{Ni}-\mathrm{Na}}^{*}$ & $\mathrm{~mol}_{\mathrm{H}} \mathrm{m}^{-3}$ & 0.090 \\
\hline $\mathrm{C}_{\mathrm{H}, \mathrm{Na}}^{*, \mathrm{Na}}$ & $\mathrm{mol}_{\mathrm{H}} \mathrm{m}^{-3}$ & 0.340 \\
\hline $\mathrm{C}_{\mathrm{H}, \mathrm{Na}}$ & $\mathrm{mol}_{\mathrm{H}} \mathrm{m}^{-3}$ & 0.042 \\
\hline$d Q_{H} / d z$ & $\mathrm{~mol}_{\mathrm{H}} \mathrm{m}^{-1} \mathrm{~s}^{-1}$ & $6.65 \times 10^{-7}$ \\
\hline
\end{tabular}
and membrane diameter/thickness, while gas and $\mathrm{Na}$ phase resistances depend on both hydrogen diffusivities and fluid properties.

By fixing geometry and physical parameters, the system composed by the three Eqs. (2.13)-(2.15) can be solved: hydrogen concentrations and hydrogen mass transfer rate per unit length $d Q_{H} / d z$ are calculated analytically. Some geometrical parameters are fixed depending on the experimental constraints: the shell diameter should fit with the sodium loop characteristic, while the membrane diameter and thickness have to be coherent with the mechanical resistance criteria, according to ASME B31.1:

Minimum thickness $=\frac{P 2 r_{0}}{2 S E+2 Y P}+C \quad[$ inch $]$

where $P$ [psig] is the design pressure, $S$ is the material allowable stress (psi), $E$ is the joint factor, $Y$ is the wall thickness coefficient and $C$ is the corrosion allowance [inch]. In particular, for a design pressure of $10 \mathrm{bar}$, the minimum required thickness is around $50 \mu \mathrm{m}$.

Results for 4 membranes of diameter $7.2 \mathrm{~mm}$ and $300 \mu \mathrm{m}$ thickness, which are common dimensions for hydrogenmetres, are reported in Table 1.

A first remark is that, for these fixed physical conditions, there is a great difference between the three mass transfer coefficients; in particular, gas phase has the highest value, 3 orders of magnitude bigger than the nickel, which is by far the lowest. Sodium mass transfer is in the middle between them, one order of magnitude bigger than nickel. This means that the highest resistance to the hydrogen mass transfer is given by the nickel membrane. The second remark concerns the impact of gas and sodium phase on the hydrogen transfer rate: by considering Eq. (2.14), the terms in brackets corresponds to the difference $\left(\mathrm{C}_{\mathrm{H}, \mathrm{Ni} \text {-gas }}^{*}-\mathrm{C}_{\mathrm{H}, \mathrm{Ni}-\mathrm{Na}}^{*}\right)$; the ratio $\mathrm{C}_{\mathrm{H}, \mathrm{Ni}-\mathrm{gas}}^{*} / \mathrm{C}_{\mathrm{H}, \mathrm{Ni}-\mathrm{Na}}^{*}$ is around 130 and their difference is practically equivalent to $\mathrm{C}_{\mathrm{H}, \mathrm{Ni} \text {-gas }}^{*}$, since then the second term can be neglected. This is the physical result given by the so high mass transfer resistance of the membrane; moreover, the difference 


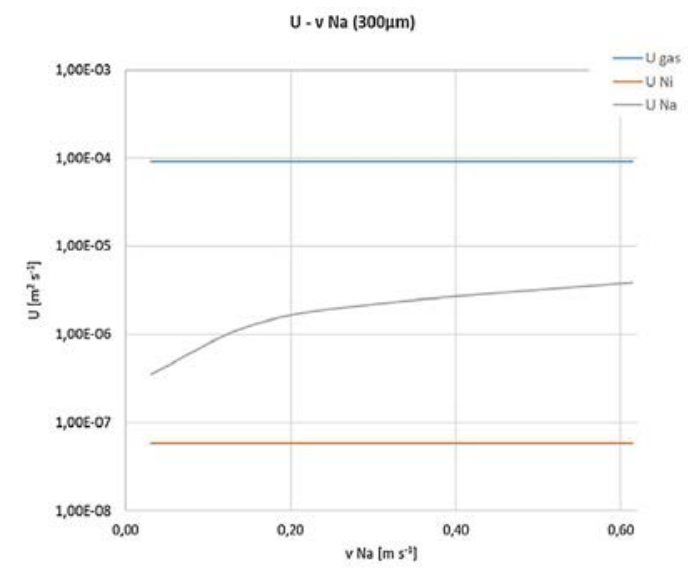

a

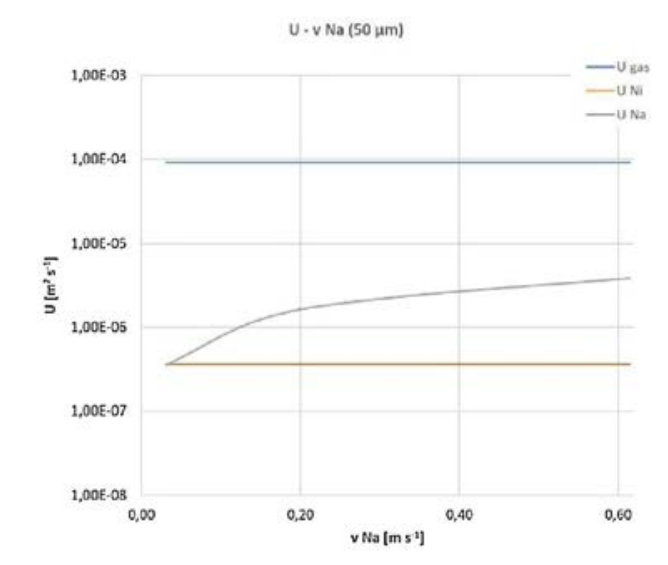

C

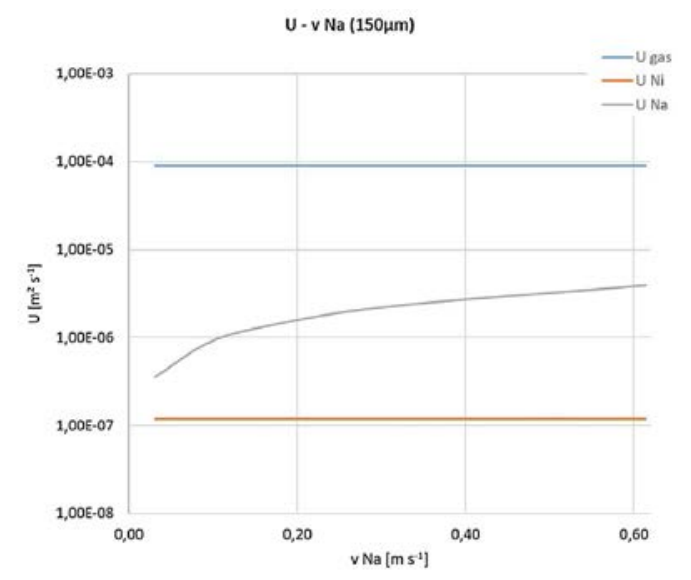

b

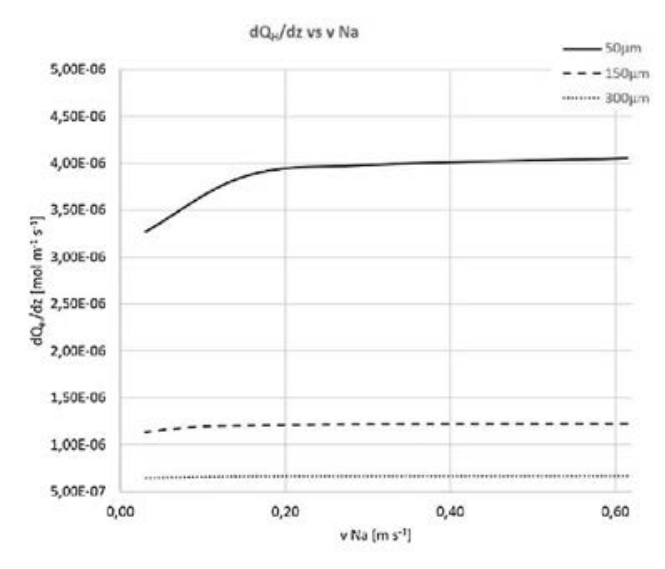

d

Fig. 2 - Influence of Na velocity on mass transfer resistances in gas, $\mathrm{Ni}$ and $\mathrm{Na}$ phase, for three membrane thicknesses $50 \mu \mathrm{m}$ (c), $150 \mu \mathrm{m}$ (b) and $300 \mu \mathrm{m}$ (a). Influence on hydrogen transfer rate (d).

in concentrations across the membrane is so high that variations on the Na side seems to have no effect on the hydrogen transfer rate, while it is strongly dependent from the gas side concentration variations.

A sensitivity analysis on physical parameters $T$, Qgas, $P_{\text {gas }}$ and $v_{\mathrm{Na}}$ reveals that, even for a sensible variation within the operation range, no noticeable variation on the three mass transfer resistances behaviour is found. In particular, when the gas phase is characterized by a laminar flow and the $\mathrm{Na}$ phase by a turbulent flow, the most important resistance to hydrogen transfer is found to be always in the membrane. A more important influence of $v_{\mathrm{Na}}$ on the $\mathrm{Na}$ phase resistance is found when it is reduced enough to approach the laminar flow: in this case, the values of $U_{\mathrm{Na}}$ and $U_{\mathrm{Ni}}$ are closer, but their difference does not produce a significant effect on the hydrogen transfer rate as shown in Fig. 2a . Finally, the absolute value of the hydrogen mass transfer rate per unit length is mainly determined by the temperature and by the two gas phase parameters: gas pressure and hydrogen molar concentration; no significant influence can be provided by Na phase within the standard operation range.

The same analysis was repeated for lower membrane thickness: for a value of $50 \mu \mathrm{m}$, which gets close to the minimum thickness for mechanical resistance, the nickel mass transfer resistance is diminished by a factor 6 ; on the other hand, the sodium phase resistance can have a significant effect only if the $\mathrm{Na}$ flowrate $\left(\dot{\mathrm{V}}_{\mathrm{Na}}\right)$ is reduced by a factor 10 , to
$0.1 \mathrm{~m}^{3} / \mathrm{h}$, bringing the Na velocity to approach the laminar regime $(\operatorname{Re} \sim 2000)$. In this particular condition, the hydrogen mass transfer rate can be significantly reduced of $25 \% \mathrm{com}$ pared to the nominal case at $\dot{V}_{\mathrm{Na}}=1 \mathrm{~m}^{3} / \mathrm{h}$. For an intermediate thickness of $150 \mu \mathrm{m}$, the same Na flowrate decrease reduces the hydrogen transfer rate of about $10 \%$ of nominal value. The influence of the Na phase velocity, for the three thickness $50 \mu \mathrm{m}, 150 \mu \mathrm{m}$ and $300 \mu \mathrm{m}$ are reported in Fig. 2.

This analysis demonstrates that, for enough thick membranes, the hydrogen mass transfer from the gas phase to liquid sodium is limited by the permeation through the nickel membrane; its mass transfer resistance is so high and the concentration difference between gas and Na phase so important, that the single permeation equation (i.e. Richardson's law) could estimate accurately the local hydrogen transfer rate. The difference in concentrations between bulk and membrane interface, both on gas phase and on Na phase, could be neglected without any significant effect on the global hydrogen mass transfer, so that Eq. (2.14) becomes:

$$
\begin{gathered}
\mathrm{dQ}_{\mathrm{H}, \mathrm{Ni}}=p e_{\mathrm{Ni}}(\mathrm{T}) * \frac{2 \pi}{\ln \left(r_{\mathrm{o}} / r_{\mathrm{i}}\right)}\left(\sqrt{\mathrm{RTC}_{\mathrm{H}_{2} \mathrm{gas}}}-\frac{\mathrm{C}_{\mathrm{H}, \mathrm{Na}}}{\mathrm{K}_{\mathrm{S}, \mathrm{Na}}(\mathrm{T})}\right) d z \\
{\left[\mathrm{~mol} \mathrm{~s}^{-1}\right]}
\end{gathered}
$$

where $\mathrm{C}_{\mathrm{H}_{2} \text { gas }}^{*}, \mathrm{C}_{\mathrm{H}, \mathrm{Na}}^{*}$ are replaced by $\mathrm{C}_{\mathrm{H}_{2} \text { gas }}, \mathrm{C}_{\mathrm{H}, \mathrm{Na}}$ and the product $K_{\mathrm{S}, \mathrm{Ni}} D_{\mathrm{S}, \mathrm{Ni}}$ gives the permeability coefficient $p e_{\mathrm{Ni}}$. 


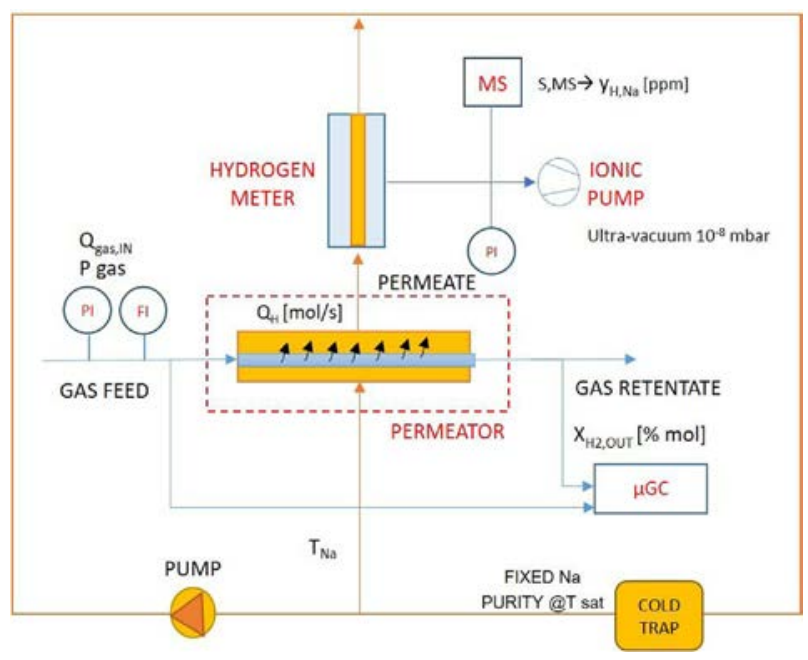

Fig. 3 - Experimental set-up for hydrogen permeation towards liquid sodium.

\section{Experimental set-up and measurement technique}

A permeator prototype has been designed to be tested inside a sodium loop, operating in conditions similar to a SFR secondary circuit. A shell and tubes configuration is chosen, where multiple nickel membranes are fixed inside a stainless steel shell: a gas mixture containing hydrogen flows inside the tubular membranes, while the liquid sodium circulates into the shell, in contact with membrane's external side. Some constraints are imposed: the membrane mechanical resistance to temperature and gas pressure, the operating conditions and geometrical dimension of the experimental loop and security considerations, which impose to work with a gas mixture containing hydrogen below the flammability limit (i.e. $\mathrm{X}_{\mathrm{H}_{2} \text { gas }}<$ $4 \%)$.

Eq. (2.18) is integrated along the axial direction, coupled to the hydrogen mass balance in gas and Na phase, in order to calculate $\mathrm{Q}_{\mathrm{H}}$, the total hydrogen permeation flowrate from gas phase to sodium. The permeator design is sized in order to have a sensible variation of $\mathrm{Q}_{\mathrm{H}}$, in function of the physical parameters of the system, which can be controlled and detected by the measurement devices described below. In particular, gas pressure, which directly acts on the hydrogen partial pressure, and temperature are identified as the two main driving factors of the permeation rate. The permeator prototype is installed in a fully equipped sodium facility in CEA Cadarache (see Fig. 3): it is constituted by a closed loop of 48 litres where sodium can be heated up to $450^{\circ} \mathrm{C}$, a test section which can be isolated from the rest of the loop, a magnetic pump which makes sodium circulating into the circuit at a maximum flowrate of $2 \mathrm{~m}^{3} / \mathrm{h}$, a cold trap system which can purify sodium down to minimum hydrogen concentration around $50 \mathrm{wppb}$, a flowmeter, a hydrogen-meter (SPHYNX) and temperature sensors. The permeator is installed in the test section connected to a gas circuit, which allows to send a gas mixture $\left(\mathrm{Ar}+3 \%\right.$ (molar) $\mathrm{H}_{2}$ ) at controlled pressure and flowrate inside the nickel membranes. During permeation tests, sodium circulates inside the test section, flowing firstly into the permeator shell, then into the hydrogen-meter. Before to start a permeation test, sodium circulates in the cold trap section, in order to be purified at a certain equilibrium concentration, corresponding to its cold point $[\mathrm{H}]$ : when permeation test starts, the cold trap section is isolated, so that sodium circulating in the permeator is enriched with hydrogen, until reaching a new equilibrium concentration.

A redundant measurement system is provided, in order to evaluate the hydrogen permeation rate, both from gas phase and Na phase measurements.

In gas phase, a hydrogen mass balance on the feed/retentate side is applied: to do so, total feed gas flowrate and hydrogen concentration at feed/retentate side are measured. Gas flowrate is measured by a Mass Flowmeter with a relative standard uncertainty of $0.9 \%$. Hydrogen inlet concentration is equal to the feed bottle concentration: its value is of $2.926 \% \pm 0.059 \%$ given at a $95 \%$ confidence interval. Hydrogen concentration in retentate gas phase is measured during permeation tests by a gas chromatograph, with a relative standard uncertainty of around $1 \%$ of measured value.

The hydrogen permeation flowrate can be calculated by applying hydrogen and total mass balance to the permeator, as follows:

$$
\begin{aligned}
& \mathrm{Q}_{\text {gasin }}=\mathrm{Q}_{\text {gas } r}+\mathrm{Q}_{\mathrm{H}_{2} p} \quad[\mathrm{~mol} \mathrm{~s} \\
& \mathrm{Q}_{\text {gas in }} \mathrm{X}_{\mathrm{H}_{2} \text { in }}=\mathrm{Q}_{\text {gas } r} \mathrm{X}_{\mathrm{H}_{2} r}+\mathrm{Q}_{\mathrm{H}_{2} p} \quad\left[\mathrm{~mol} \mathrm{~s}^{-1}\right]
\end{aligned}
$$

By combining the two balances we obtain

$\mathrm{Q}_{\mathrm{H}_{2} p}=\mathrm{Q}_{\mathrm{gasin}} \frac{\mathrm{X}_{\mathrm{H}_{2} \text { in }}-\mathrm{X}_{\mathrm{H}_{2} r}}{1-\mathrm{X}_{\mathrm{H}_{2} r}}=\mathrm{Q}_{\mathrm{gasin}} \frac{\Delta \mathrm{X}_{\mathrm{H}_{2}}}{1-\mathrm{X}_{\mathrm{H}_{2} r}} \quad\left[\mathrm{~mol} \mathrm{~s}^{-1}\right]$

In sodium phase, an indirect measurement of the hydrogen permeation flowrate can be obtained thanks to the hydrogenmeter: in fact, knowing the detection membrane geometrical parameters and permeability, it gives the values of $\mathrm{C}_{\mathrm{H}, \mathrm{Na}}$ by means of Eq. (1.2). As permeation test begins, the hydrogenmeter, which is located just after the permeator, detects an increment of $\mathrm{C}_{\mathrm{H}, \mathrm{Na}}$. Since sodium is continuously circulating in the closed loop, as long as the permeation goes on, $\mathrm{C}_{\mathrm{H}, \mathrm{Na}}$ will increase; once permeation is stopped (i.e. hydrogen gas flowrate at permeator inlet is turn off), sodium will progressively reach an equilibrium value of $\mathrm{C}_{\mathrm{H}, \mathrm{Na}}$, meaning that the permeated hydrogen is homogeneously dissolved in sodium loop.

Under the hypotheses that permeation flow is constant and $\mathrm{C}_{\mathrm{H}, \mathrm{Na}}$ is homogeneous in the loop at final equilibrium, an indirect measurement of $\mathrm{Q}_{\mathrm{H} p}\left[\mathrm{~mol}_{\mathrm{H} 2} / \mathrm{S}\right]$ can be obtained as follows:

$\mathrm{Q}_{\mathrm{H} p}=\mathrm{V}_{\mathrm{Na}} \frac{\mathrm{C}_{\mathrm{H}, \mathrm{Na}}\left(\mathrm{t}_{\text {eq }}\right)-\mathrm{C}_{\mathrm{H}, \mathrm{Na}}\left(\mathrm{t}_{0}\right)}{t_{\text {perm }}} \quad\left[\mathrm{mol}_{\mathrm{H}_{2}} / \mathrm{s}\right]$

where $\mathrm{C}_{\mathrm{H}, \mathrm{Na}}\left(\mathrm{t}_{0}\right)\left[\mathrm{mol} \mathrm{m}^{-3}\right]$ is the hydrogen molar concentration in sodium at the initial time and $\left[\mathrm{mol} \mathrm{m}^{-3}\right]$ at the equilibrium, $t_{\text {perm }}[s]$ is the permeation time (i.e. the time during which the permeator is fed with gas mixture) and $\mathrm{V}_{\mathrm{Na}}$ is the sodium volume circulating in the circuit.

\section{Permeation against vacuum results and discussion}

The final goal of the experimental test is to evaluate, for different operating conditions, the value of $\mathrm{Q}_{\mathrm{H} p}$ and to verify if it follows a theoretical law derived from Eq. (2.18), aiming to describe the global permeation over the entire prototype geometry at the pilot-scale. In particular, the model in Section 


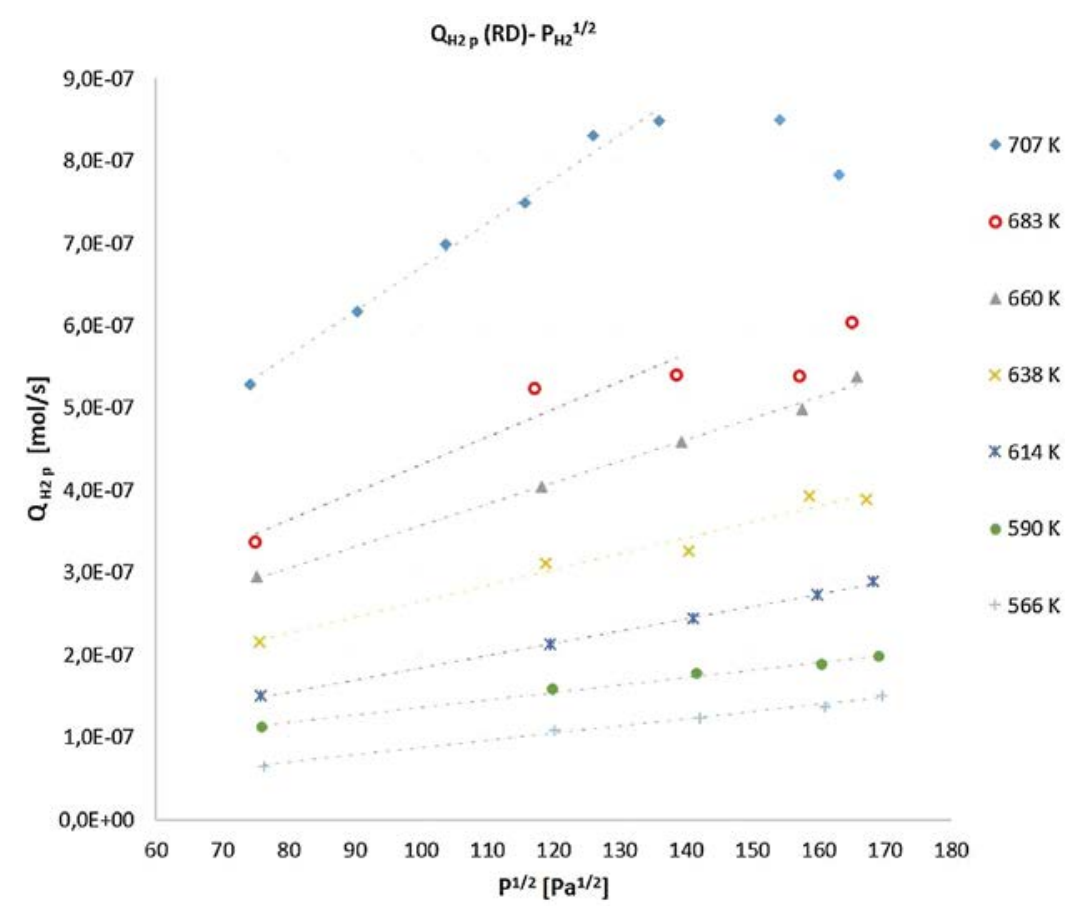

Fig. 4 - Experimental measurements of hydrogen permeation against vacuum.

2 has showed that the hydrogen partial pressure in sodium is much lower than the gas feed side partial pressure, and that it should have no influence on permeation flowrate. Substantially, it means that the local permeation law over an infinitesimal tube length $d z$ can be reduced to:

$d Q_{H}=p e_{N i}(T) * \frac{2 \pi}{\ln \left(r_{0} / r_{i}\right)}\left(\sqrt{P_{\text {gas }} X_{\mathrm{H}_{2} g a s}} \quad d z \quad\left[\mathrm{~mol} \mathrm{~s}^{-1}\right]\right.$

where the gas side hydrogen partial pressure is expressed by means of the gas total pressure and the molar fraction $\mathrm{X}_{\mathrm{H}_{2} \text { gas }}$. In this case, if the permeate side was constituted by an equivalent very low gas pressure, typically an ultra-vacuum, the permeation should be the same, since the hydrogen in feed side has always a predominant effect on the permeate side. For this reason, the permeator is preliminary tested against vacuum, i.e. sodium does not circulate into the shell, but it is maintained under vacuum by a pump. This test should reveal if the hypotheses made to describe the permeation process are valid; moreover, these first results constitute a benchmark for the permeation tests in presence of sodium. As a general remark for this paragraph, permeation against vacuum is always referred to $\mathrm{H}_{2}$ molecules instead of $\mathrm{H}$ atoms for practical reasons; the corresponding $\mathrm{H}$ atoms permeation rate is obtained by multiplying it by two.

When we consider the prototype geometry, since $X_{\mathrm{H}_{2} \text { gas }}$ varies axially along the permeator membranes as an effect of permeation, a mean hydrogen partial pressure is calculated by coupling Eq. (4.1) with the hydrogen mass transfer in gas phase, assumed to be plug-flow:

$\sqrt{\overline{\overline{\mathrm{P}_{2}}}}=\sqrt{\mathrm{P}_{\text {gas }}} \sqrt{\overline{\overline{\mathrm{X}_{\mathrm{H}_{2}}}}}=\sqrt{\mathrm{P}_{\text {gas }}} \frac{\mathrm{X}_{\mathrm{H}_{2} r}-\mathrm{X}_{\mathrm{H}_{2} \text { in }}}{2\left(\sqrt{\mathrm{X}_{\mathrm{H}_{2} r}}-\sqrt{\mathrm{X}_{\mathrm{H}_{2} \text { in }}}\right.} \quad\left[\mathrm{Pa}^{0.5}\right]$

Furthermore, since the membrane thickness is small compared to its diameter, the tubular geometry can be approximated to a flat sheet. By referring to $\mathrm{H}_{2}$ molecules instead of $\mathrm{H}$ atoms, and integrating Eq. (4.1) along the membrane's axial direction, together with the gas phase convective transport between feed and retentate side, we obtain the following integrated law:

$\mathrm{Q}_{\mathrm{H}_{2}, p}=\frac{\mathrm{A}}{\delta} p e_{0} e^{-E_{p} / \mathrm{RT}} \sqrt{\overline{\mathrm{P}_{\mathrm{H}_{2}}}}\left[\mathrm{~mol} \mathrm{~s}^{-1}\right]$

where $A$ is the total membrane surface calculated at the mean membrane diameter, $p e_{0}$ and $E_{p}$ are the permeability preexponential factor and activation energy respectively. Eq. (4.3) is an integrated form of the local Richardson's law over the entire prototype geometry, including the hydrogen convective transport in gas phase as well, which provides the global permeation flow for our experiments at the pilot-scale. In our analysis we lead back experimental measurements to this form in order to read the results in the light of a theoretical basis and to estimate the permeability coefficients $p e_{0}$ and $E_{p}$.

The prototype was tested at different temperatures and gas pressures, by sending a gas flowrate of $200 \mathrm{Nml} / \mathrm{min}$ inside nickel membranes. For each tested condition, the hydrogen permeation flowrate is obtained both from concentration measurements in retentate side with $\mu \mathrm{GC}$ (see Eq. (3.1)) and from pressure measurements in the vacuum permeate side. A data reconciliation method allows us to obtain reconciled data (RD) from the two measurements by considering their uncertainties. The relative uncertainty on $\mathrm{Q}_{\mathrm{H}_{2}, p}$ measurements is of $\pm 10 \%$, coming mainly from the calibration procedures of instruments; it is independent from gas pressure and temperature, since a gas sample is analyzed at stable conditions for each test. The temperature is calculated as the mean value of three distinct thermocouples placed on the permeator: temperature is found to be non-uniform along the membrane, with percentage deviations from $5 \%$ to $11 \%$ of the mean value.

The measured $\mathrm{Q}_{\mathrm{H}_{2}, p}$ against $\sqrt{\overline{\overline{\mathrm{H}_{2}}}}$ are reported in Fig. 4, for mean temperatures from $566 \mathrm{~K}$ to $707 \mathrm{~K}$. The law of Eq. (4.3) is nearly well respected in term of linear dependence with the square root of the hydrogen partial pressure. A deviation from the linearity has been found for the two highest gas pres- 


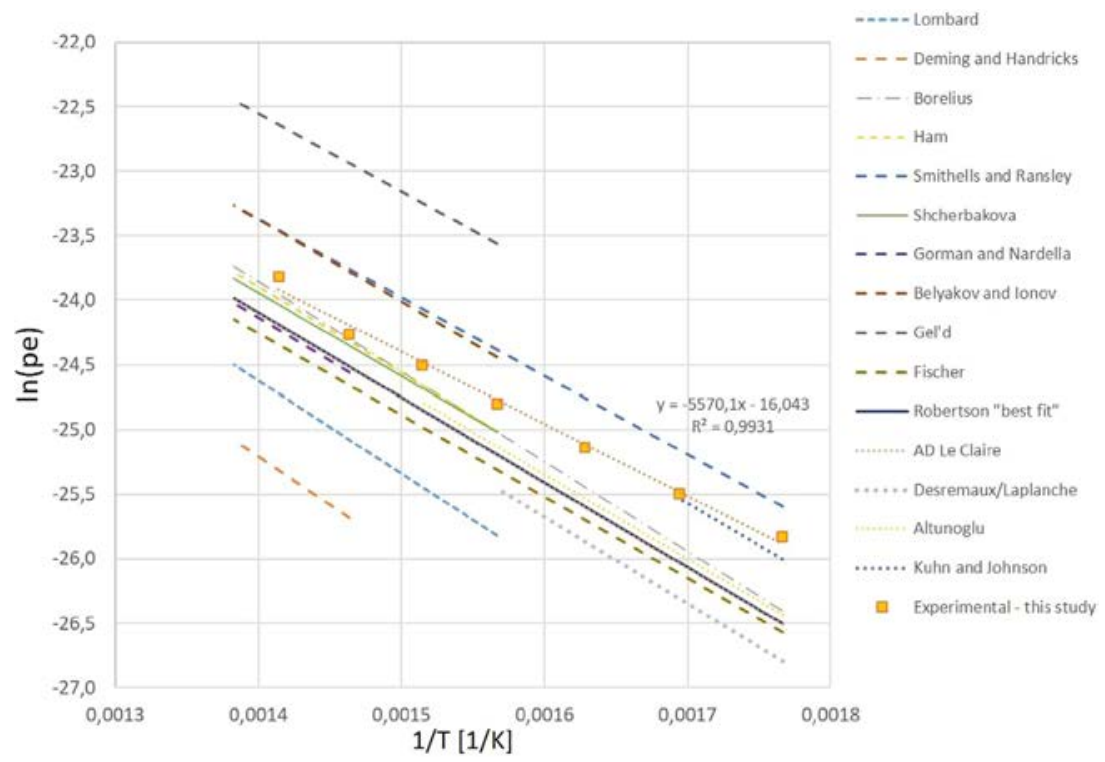

Fig. 5 - Experimental measurements of hydrogen permeation against vacuum compared to literature results for pure nickel membranes.

\begin{tabular}{|c|c|c|c|c|}
\hline \multirow[t]{2}{*}{ Reference } & \multicolumn{2}{|l|}{ Range $T$} & \multirow[t]{2}{*}{$p e_{0}\left(\mathrm{~mol}_{\mathrm{H}_{2}} \mathrm{~m}^{-1} \mathrm{~s}^{-1} \mathrm{~Pa}^{-0.5}\right)$} & \multirow[t]{2}{*}{$E_{p}\left(\mathrm{~J} \mathrm{~mol}^{-1}\right)$} \\
\hline & $\mathrm{T} \min (\mathrm{K})$ & $\mathrm{T} \max (\mathrm{K})$ & & \\
\hline Lombard (Sakamoto, 2000) & 643 & 966 & $44,810^{-7}$ & 59,410 \\
\hline Deming and Handricks (Sakamoto, 2000) & 676 & 1018 & $39,410^{-7}$ & 62,130 \\
\hline Borelius and Lindblom (Sakamoto, 2000) & 453 & 823 & $72,610^{-7}$ & 57,740 \\
\hline Ham (Sakamoto, 2000) & 649 & 873 & $46,510^{-7}$ & 55,310 \\
\hline Smithells and Ransley (Sakamoto, 2000) & 521 & 1023 & $34,210^{-7}$ & 50,380 \\
\hline Shcherbakova (Sakamoto, 2000) & 623 & 873 & $31,810^{-7}$ & 53,350 \\
\hline Gorman and Nardella (Sakamoto, 2000) & 673 & 1123 & $36,010^{-7}$ & 55,230 \\
\hline Belyakov and Ionov (Sakamoto, 2000) & 623 & 873 & $54,210^{-7}$ & 53,140 \\
\hline Gel'd (Sakamoto, 2000) & 633 & 1123 & $75,510^{-7}$ & 50,210 \\
\hline Fischer (Sakamoto, 2000) & 423 & 996 & $19,910^{-7}$ & 52,430 \\
\hline Robertson "best fit" (Robertson, 1973) & 297 & 1333 & $33,310^{-7}$ & 54,560 \\
\hline AD Le claire (Le Claire, 1983) & 293 & 1343 & $33,310^{-7}$ & 54,598 \\
\hline Desremaux/Laplanche (Desreumaux and Laplanche, 1984) & 473 & 635 & $34,610^{-7}$ & 56,106 \\
\hline Altunoglu (Altunoglu et al., 1991) & 373 & 673 & $33,510^{-7}$ & 54,240 \\
\hline Kuhn and Johnson (Kuhn and Johnson, 1991) & 273 & 600 & $59,210^{-7}$ & 54,900 \\
\hline This work & 566 & 707 & $1.12 \times 10^{-7}$ & 46,499 \\
\hline
\end{tabular}

sures (9 and 10 bar) at the two highest temperatures tested $(683 \mathrm{~K}$ and $707 \mathrm{~K})$ : in these conditions, where the maximum permeation rate should be reached according to Eq. (4.3), the hydrogen permeation decreases or stalls instead of increasing; no clear explanation was found at this stage, but a possible cause could be attributed to the gas phase polarization effect, becoming important at higher permeation rates and gas pressures (Mourgues and Sanchez, 2005). The four experimental points deviating from linearity are not considered for further analysis.

By isolating the permeability coefficient in Eq. (4.3) and by applying a logarithm to both sides, one obtains the following form:

$\ln \frac{\mathrm{Q}_{\mathrm{H}_{2}, p}}{\mathrm{~A} / \delta \sqrt{\overline{\mathrm{P}_{\mathrm{H}_{2}}}}}=-\frac{E_{p}}{R} \frac{1}{\mathrm{~T}}+\ln \left(p e_{0}\right)$

The results shown in Fig. 4 can be then represented using this equation form; in this way the temperature dependence can be verified; in particular, for each temperature, a dispersion of experimental results was found in the order of $\pm 10 \%$. Therefore, for a given temperature, a mean value of the ratio
$\mathrm{Q}_{\mathrm{H} 2, \mathrm{p}} /\left(\mathrm{A} / \delta \sqrt{\overline{\mathrm{P}_{\mathrm{H}}}}\right)$ is calculated by regression starting from experimental data presented in Fig. 4. In Fig. 5, the logarithm of $\mathrm{Q}_{\mathrm{H} 2, \mathrm{p}} /\left(\mathrm{A} / \delta \sqrt{\overline{\mathrm{P}_{2}}}\right)$ mean values is plotted against $1 / \mathrm{T}$, and they are compared with literature correlations reported in the Sakamoto's review (Sakamoto, 2000), concerning nickel permeation properties. It is worth noting that the experimental results are well in accordance with the dispersion of previous results and they show a good linear dependence against the inverse of temperature, thus confirming the validity of Eq. (4.4). The linear regression of the experimental mean values with $1 / \mathrm{T}$ gives the following equation:

$\ln \frac{\mathrm{Q}_{\mathrm{H}_{2}, p}}{\mathrm{~A} / \delta \sqrt{\overline{\mathrm{P}_{\mathrm{H}_{2}}}}}=-5570.1 \frac{1}{\mathrm{~T}}+16.043$

which, compared to Eq. (4.4), allows us to obtain an estimation of the permeability coefficients. In particular, $E_{p}=46,309$ $\left[\mathrm{J} \mathrm{mol}^{-1}\right]$ and $p e_{0}=1.0810^{-7} \mathrm{~s}\left[\mathrm{~mol} \mathrm{~m}^{-1} \mathrm{~s}^{-1} \mathrm{~Pa}^{-0.5}\right]$.

Table 2 resumes the literature correlations found in Sakamoto's review, as well as some other works on nickel membranes, compared to this work. It is worth noting that 
previous works are mainly conducted by measuring permeation on micro-scale nickel samples of plane geometry, with a static gas in contact with the membrane, in well controlled and homogeneous conditions (i.e. the sample is placed in a closed hot cell with stable temperature, hydrogen partial pressure is uniform on the membrane). In this case, comparison of experimental results with the local Richardson's law is legitimated. This work gives a slightly lower pre-exponential coefficient and activation energy, if compared to literature; actually, this difference is not very significant if we look at the dispersion in Fig. 5. Nevertheless, particular regard should be payed to the fact that our experiments were conducted on a multiple tubular membranes prototype at the pilot-scale, taking into account non-uniform membrane temperature and hydrogen partial pressure variation along the membrane due to the gas circulation. Moreover, our coefficients are obtained by comparison with an integrated law (Eq. (4.3)) which is based on theoretical hypothesis and assumptions, potentially not fully respected during experiments. Finally, the objective of this comparison is not to validate a new nickel permeability correlation, but rather to verify the prototype performances by giving a benchmark case for future test with sodium.

\section{Conclusions}

Hydrogen mass transfer from a gas mixture to liquid sodium by permeation through a nickel membrane has been described with a model taking into account the mass transfer resistances inside flowing gas, flowing liquid sodium and nickel membrane. It demonstrates that, for a membrane thickness above $50 \mu \mathrm{m}$, when Na flow regime is turbulent, the most relevant resistance to hydrogen mass transfer is provided by the nickel membrane diffusion. Moreover, if the hydrogen concentration in sodium is low enough (below $1 \mathrm{wppm}$ ), this term can be neglected if compared to the hydrogen partial pressure in gas, which is found to mainly drive the permeation flow.

In the light of these results, the simple Richardson's law can be used to describe locally the permeation; an experimental prototype composed by four tubular nickel membranes has been designed. An experimental sodium loop is used to test the prototype in a gas-sodium configuration at pilot-scale; in order to estimate the hydrogen permeation flowrate, different measurement techniques are provided both in gas and liquid sodium phase. A first characterization of the prototype has been performed, by realizing permeation test against vacuum at different gas pressures and temperatures: an integrated form of the local Richardson's law describing the entire prototype geometry, coupled to the hydrogen convective transport in gas phase, is provided to analyze the results. Experiments show a good agreement with the integrated law and permeability values are coherent with previous studies found in literature realized at the micro-scale. Nevertheless, slight deviations can be traced back to main pilot-scale effects, such as membrane non-uniform temperature and hydrogen partial pressure variation along the membrane. These results provide as well a good benchmark for future tests, which will be carried out in a gas-sodium configuration.

\section{References}

Altunoglu, A.K., Blackburn, D.A.N.St., Braithwaite, J., Grant, D.M., 1991. Permeation of hydrogen through nickel foils: surface reaction rates at low temperatures. J. Common Met. 172-174
(Aug), 718-726,

http://dx.doi.org/10.1016/0022-5088(91)90195-A.

Cachon, L., et al., 2012. Innovative power conversion system for the French SFR prototype. In: ASTRID, ICAPP'12, Chicago, IL (United States), 24-28 June, https://www.osti.gov/biblio/22105979-innovative-powerconversion-system-french-sfr-prototype-astrid.

Catalano, J., Giacinti Baschetti, M., Sarti, G.C., 2009. Influence of the gas phase resistance on hydrogen flux through thin palladium-silver membranes. J. Membr. Sci. Sep. 339 (1), 57-67, http://dx.doi.org/10.1016/j.memsci.2009.04.032.

Cussler, E., 2009. Fundamentals of mass transfer. In: Diffusion: Mass Transfer in Fluid Systems (Cambridge Series in Chemical Engineering). Cambridge University Press, Cambridge, pp. 237-273, http://dx.doi.org/10.1017/CBO9780511805134.010.

Desreumaux, J., Laplanche, G., 1984. Mesure de permeabilité à l'hydrogène des membranes de Nickel. CEA Centre d'Etudes Nucleaires de Cadarache, Note technique 1436-84/039.

Faizal, H.M., Kawasaki, Y., Yokomori, T., Ueda, T., 2015. Experimental and theoretical investigation on hydrogen permeation with flat sheet $\mathrm{Pd} / \mathrm{Ag}$ membrane for hydrogen mixture with various inlet $\mathrm{H}_{2}$ mole fractions and species. Sep. Purif. Technol. 149 (Jul), 208-215, http://dx.doi.org/10.1016/j.seppur.2015.05.003.

Garcinuño, B., Rapisarda, D., Moreno, C., Sanz, J., Ibarra, Á., 2018. Design of a system for hydrogen isotopes injection into Lead-Lithium. Fusion Eng. Des. 137 (Dec), 427-434, http://dx.doi.org/10.1016/j.fusengdes.2018.10.006.

Gnanasekaran, T., 1999. Thermochemistry of binary Na-NaH and ternary $\mathrm{Na}-\mathrm{O}-\mathrm{H}$ systems and the kinetics of reaction of hydrogen/water with liquid sodium - a review. J. Nucl. Mater. Sep. 274 (3), 252-272, http://dx.doi.org/10.1016/S0022-3115(99)00072-0.

Gnanasekaran, T., Mahendran, K.H., Sridharan, R., Ganesan, V., Periaswami, G., Mathews, C.K., 1990. An electrochemical hydrogen meter for measurement of dissolved hydrogen in liquid sodium. Nucl. Technol. 90 (3 (Jun)), 408-416, http://dx.doi.org/10.13182/NT90-A34404.

He, G., Mi, Y., Lock Yue, P., Chen, G., 1999. Theoretical study on concentration polarization in gas separation membrane processes. J. Membr. Sci. 153 (2 (Feb)), 243-258, http://dx.doi.org/10.1016/S0376-7388(98)00257-9.

Kuhn, D.K., Johnson, H.H., 1991. Transient analysis of hydrogen permeation through nickel membranes. Acta Metall. Mater. 39 (11 (Nov)), 2901-2908, http://dx.doi.org/10.1016/0956-7151(91)90106-B.

Latge, C., 2009. Sodium Quality Control; French Developments from Rapsodie to EFR, IAEA-CN-176, Paper 02/02 Kyoto (Japan), 7-11 December., pp. 104-105, http://inis.iaea.org/Search/search.aspx?orig_q=RN:41069931.

Le Claire, A.D., 1983. Permeation of gases through solids. UKAEA Atomic Energy Research Establishment, AERE-R-10846, http://inis.iaea.org/Search/search.aspx?orig_q=RN:14786384.

Maupre, J.-P., 1978. Study of the Na-C-O and Na-H-O Ternary Systems in the Sodium Rich Corner, Technical Report No. 4905, CEA, France.

McKee, 1977. A calibration system for hydrogen meters in sodium. Trans. Am. Nucl. Soc. 27, 253.

Mourgues, A., Sanchez, J., 2005. Theoretical analysis of concentration polarization in membrane modules for gas separation with feed inside the hollow-fibers. J. Membr. Sci. 252 (1 (Apr)), 133-144, http://dx.doi.org/10.1016/j.memsci.2004.11.024.

Paumel, K., 2012. Comparative Tests of Two Hydrogen-meter Technologies in the Phenix Reactor. NPIC\&HMIT, San Diego, CA.

Richardson, O.W., Nicol, J., Parnell, T., 1904. I. The diffusion of hydrogen through hot platinum. Lond. Edinb. Dublin Philos. Mag. J. Sci. 8 (43 (Jul)), 1-29, http://dx.doi.org/10.1080/14786440409463168.

Robertson, W.M., 1973. Hydrogen permeation, diffusion and solution in nickel. Z. Fuer. Met. Res. Adv. Tech. 64 (6), 436-443. 
Sakamoto, Y., 2000. Nickel-hydrogen system. Solid State Phenom. 73-75, 137-206.

Vissers, D.R., Holmes, J.T., Bartholme, L.G., Nelson, P.A., 1974. A Hydrogen-activity meter for liquid sodium and its application to hydrogen solubility measurements. Nucl. Technol. 21 (3 (Mar)), 235-244, http://dx.doi.org/10.13182/NT74-A31394.

Webb, R.W., 1964. Hydrogen Permeation Through Metals, Other Information: Orig. Receipt Date: 31-DEC-64, Apr. 27

https://digital.library.unt.edu/ark:/67531/metadc865810/.
Whittingham, A.C., 1976. An equilibrium and kinetic study of the liquid sodium-hydrogen reaction and its relevance to sodium-water leak detection in LMFBR systems. J. Nucl. Mater. 60 (2 (May)), 119-131,

http://dx.doi.org/10.1016/0022-3115(76)90157-4. 